\title{
The incidence and risk factors of peripherally inserted central catheter-related infection among cancer patients
}

\author{
Yufang Gao',* \\ Yuxiu Liu ${ }^{2, *}$ \\ Xiaoyan $\mathrm{Ma}^{3}$ \\ Lili Wei ${ }^{4}$ \\ Weifen Chen $^{2}$ \\ Lei Song ${ }^{2}$
}

'President's Office, ${ }^{2}$ Oncology Department, the Affiliated Hospital of Qingdao University, Qingdao, ${ }^{3}$ Intensive Care Unit, Shanghai East Hospital, Shanghai, ${ }^{4}$ Nursing Department, the Affiliated Hospital of Qingdao University, Qingdao, People's Republic of China

*These authors contributed equally to this work

\author{
This article was published in the following Dove Press journal: \\ Therapeutics and Clinical Risk Management \\ 22 May 2015 \\ Number of times this article has been viewed
}

Background: As the use of peripherally inserted central catheters (PICCs) increased in chemotherapy, the identification of complications and risk factors became essential to prevent patient harm. But little is known about PICC-related infection and risk factors among patients with cancer. Our study was to identify the prevalence, patterns, and risk factors of catheterrelated infections associated with PICCs.

Methods: A 3-year prospective cohort study was conducted in a university-affiliated hospital. All patients with cancer who met inclusion criteria were enrolled. The patients were followed up until catheter removal. Tip cultures were routinely performed at the time of catheter removal. The general information was recorded at the time of PICC insertion, weekly care, and removal. Univariable and multivariable logistic regression analyses were applied for identification of risk factors. Results: In total, 912 cancer patients with 912 PICCs of 96,307 catheter days were enrolled. Ninety-four developed PICC-related infection; 46 were exit-site infection, 43 were catheter bacterial colonization, and five were PICC-related bloodstream infection. The median time from catheter insertion to infection was 98.26 days. Multivariate analysis showed StatLock fixing (odds ratio $[\mathrm{OR}]=0.555,95 \%$ confidence interval $[\mathrm{CI}]: 0.326-0.945$ ) and tip position located in the lower one-third of the superior vena cava ( $\mathrm{OR}=0.340,95 \% \mathrm{CI}$ : $0.202-0.571$ ) were associated with lower PICC infection rate. Catheter care delay (OR $=2.612,95 \% \mathrm{CI}$ : $1.373-4.969)$ and indwelling mostly in summer (OR $=4.784,95 \% \mathrm{CI}$ : $2.681-8.538)$ were associated with higher infection incidence.

Conclusion: StatLock fixing and tip position located in the lower one-third of the superior vena cava were protective factors against PICC-related infection, while catheter care delay and indwelling mostly in summer were risk factors. Policy and measures targeting these factors may be necessary to reduce the risk of infection.

Keywords: PICC, complication, clinical study, catheter-related bloodstream infection

\section{Introduction}

In recent years, the use of peripherally inserted central catheters (PICCs) has significantly increased in the People's Republic of China, especially in chemotherapy among cancer patients. ${ }^{1}$ PICCs have no mechanical complications like pneumothorax or hemorrhage associated with traditional central venous catheter (CVC) placement and provide a longer indwelling time than that associated with peripheral vascular access. Moreover, PICCs facilitate transitions from hospital to home for intermittent intravenous therapy. ${ }^{2}$ Therefore, PICCs have been demonstrated to be an outstanding tool for providing chemotherapy access in oncology patients. ${ }^{3}$

Despite the benefits of PICCs in chemotherapy, PICCs are frequently associated with severe complications including thrombophlebitis, catheter-related thrombosis,
Correspondence: Yufang Gao President's Office, the Affiliated Hospital of Qingdao University, No 16 Jiangsu Road, Shinan District, Qingdao 26600I, People's Republic of China Tel +86 I86 63608162 Email gaoyufang06I2@163.com 
and catheter-related infection (CRI), all of which contribute to patient discomfort and additional health care costs. ${ }^{4} \mathrm{Com}-$ pared to serious thrombosis complications, $\mathrm{PICC}$ infection is relatively less common. Catheter-related bloodstream infection (CRBSI) with PICCs had historically been thought to have a lower incidence than with other CVCs. ${ }^{5,6}$ However, a recent systematic review suggested the rate of PICCassociated bloodstream infections in hospitalized patients was statistically similar to that of other CVCs. ${ }^{7}$ The question whether PICCs are truly safer than other CVCs in terms of infection complication has been put forward.

As most CRBSIs occur in the intensive care unit, most the studies on PICC infection have focused on the critically ill. Studies on PICC-related infection among cancer patients are relatively few. Moreover, most of the studies were in hematogenous malignancy. ${ }^{8-11}$ The reported incidence of PICC-related bloodstream infection in cancer patients is $0-7.5 / 1,000$ catheter days, ${ }^{8,12,13}$ and the incidence of exit-site infection was reported to be $1.9 \%-60.9 \%{ }^{9,10}$ Most studies were retrospective in design and did not specify evaluation criteria for CRI or only relied on clinical suspicion of infection. No study routinely cultured all catheter tips at the time of removal in cancer patients, and only one study performed cultures in the presence of symptoms suggestive of infection in cancer patients. ${ }^{9}$ In the People's Republic of China, most cancer patients were with PICC at home during their chemotherapy interval and the indwelling time was relatively longer than most studies reported. This may add to the post-hospital infection risk. One study has suggested that the longer a catheter remains in place, the greater the risk of complications, including CRBSI. ${ }^{14}$ Therefore, identification of PICC-related infection prevalence and risk factors is significant for optimizing care and infection surveillance of oncology patients.

To explore the PICC-related infection prevalence and risk factors among cancer patients, in order to better guide clinical practice and safeguard patient safety, we conducted a prospective cohort study in a large tertiary hospital. We performed microbiological cultures for all the catheter tips at the time of removal and divided PICC-related infection into three classes: exit-site infection, bacterial colonization, and bloodstream infection.

\section{Methods}

\section{Study population and design}

A prospective cohort study was conducted from October 2011 to July 2014 in the Affiliated Hospital of Qingdao University, Qingdao, People's Republic of China, a university-affiliated, tertiary comprehensive hospital. The study was approved by the institutional review board and was conducted in compliance with the Health Insurance Portability and Accountability Act. All of the cancer patients enrolled in the study provided written informed consent.

Cancer patients who were subjected to PICC placement and had their PICC cared for once a week in our hospital were considered in the study. The inclusion criteria were as follows: 1) patients were aged at least 18 years; 2) patients were diagnosed with malignancy and needed chemotherapy by PICC; 3) patients with PICC placement by a PICC specialist nurse could come for outpatient PICC care once a week; and 4) patients agreed to catheter tip cultures at the time of removal and blood cultures in conditions of clinical suspicion of bloodstream infection. The exclusion criteria included the following: 1) PICC placement contraindication, such as catheter allergy, suspicion of systemic infection, superior vena cava (SVC) syndrome, and severe hemorrhagic disease; and 2) patients who were unable to attend weekly PICC care appointments.

\section{Data collection}

We designed a data collection case report form for every enrolled cancer patient. All the data were collected and recorded by PICC specialist nurses in our study group. Before PICC placement, general health education on PICC and our study were introduced to the patients. The patients provided written informed consent. The PICC specialist nurses recorded the date of catheter insertion and baseline demographics of each patient. Weekly care information was collected and recorded by our investigator. The content recorded weekly contained PICC-related complications, treatment, assessment of risk factors, and laboratory examination results. At the time of PICC removal, routine catheter tip culture and drug sensitivity testing were performed. For clinical suspicion of CRBSI, catheter tip culture, blood culture, and drug sensitivity testing were conducted after PICC removal. The study investigator recorded the test results. In brief, data were recorded at study entry, weekly review, and study exit. Table 1 lists the case report form content and data collection methods.

\section{PICC insertion and care}

All PICCs were inserted by our PICC specialist nurses. Portable ultrasound examination was routinely performed before PICC placement to identify a suitable vein for insertion. During insertion, maximal barrier precautions were used, including strict skin antisepsis with $2 \%$ chlorhexidine, draping of the procedural area, sterile gloves, and body gowns. 
Table I Data collection contents and methods

\begin{tabular}{|c|c|c|}
\hline Project & Contents & Collection methods \\
\hline Demographics & Name, admission number, age, gender, height, weight, etc & HIS or interview \\
\hline Clinical data and history & $\begin{array}{l}\text { Clinical diagnosis, comorbidities, chemotherapy history, surgical } \\
\text { history, trauma history, family medical history, smoking history, } \\
\text { central venous catheter history }\end{array}$ & HIS or interview \\
\hline Catheter insertion records & $\begin{array}{l}\text { Date, operator, insertion place, indication for insertion, number } \\
\text { of insertion attempts, vein and arm of insertion, the type of PICC } \\
\text { (lumens, gauge, brand), PICC adjustments, and location of catheter tip }\end{array}$ & $\begin{array}{l}\text { Recorded by PICC } \\
\text { specialist nurses }\end{array}$ \\
\hline Weekly care records & $\begin{array}{l}\text { PICC-related complications, symptom, and treatment; exit-site and } \\
\text { skin conditions; relevant symptoms and signs of infection; fixing method }\end{array}$ & Recorded by investigators \\
\hline Laboratory results & Routine blood test results, blood lipid result, blood coagulation results, etc & HIS \\
\hline Catheter removal records & $\begin{array}{l}\text { Date, indwelling time, removal reason, catheter tip culture result, } \\
\text { blood culture result, and drug sensitivity result }\end{array}$ & $\begin{array}{l}\text { HIS and recorded by } \\
\text { investigators }\end{array}$ \\
\hline
\end{tabular}

Abbreviations: HIS, hospital information system; PICC, peripherally inserted central catheter.

The PICC was inserted using the modified Seldinger technique under ultrasound guidance. The PICC was secured in place with sterile gauze and dressing. The PICC tip position was verified by chest X-ray, with subsequent adjustments made according to a radiologist's interpretation of the catheter tip position, which was ideally at the SVC inferior segment.

After PICC insertion, a standardized clinical care protocol for PICC care was followed. The second day after PICC insertion, the primary gauze and dressing were replaced with a sterile film dressing. Some PICCs were fixed with StatLock (Venetec International, San Diego, CA, USA) according to patient preference. The dressing was changed weekly or more frequently if it was not completely intact, dry, or clean. The PICCs were flushed with $10 \mathrm{~mL}$ saline and locked with $2 \mathrm{~mL}$ saline with $100 \mathrm{UI} / \mathrm{mL}$ heparin after placement, after each use, and once a week between chemotherapy without use. During our study period, antibiotic or antithrombotic prophylaxis was not routinely administered. All patients were followed up until either the PICC was removed or they met the criteria for a PICC-related bloodstream infection.

\section{Definitions}

PICC-related infection was categorized to: 1) PICC insertion local exit-site infection, defined as the presence of erythema, induration, and/or tenderness within $2 \mathrm{~cm}$ of the catheter exit site. The bacteria culture for swabs of catheter exit-sites showed positive and excluded the possibility of contamination according to Infectious Diseases Society of America recommendations..$^{15}$ 2) Bacterial colonization, defined as 15 or more colony-forming units present using the roll-plate technique or 1,000 or more colony-forming units by quantitative culture of pathogenic bacteria. ${ }^{1}$ 3) CRBSI, defined as when the same organism was isolated from the peripheral blood as from the catheter in a patient with clinical signs of infection (fever $>38^{\circ} \mathrm{C}$, chills, rigor, hypotension) and no other sources of infection according to the National Nosocomial Infections Surveillance System from the Centers for Disease Control and Prevention (CDC) (Atlanta, GA, USA) and from the Public Health Laboratory Service of the UK. ${ }^{13,15}$

Catheter care delay was defined as missed care or follow-up longer than 7 days. Indwelling time of a PICC was calculated in days from the insertion of the PICC until one of the following: 1) the date of PICC removal; or 2) the date of positive blood culture identified as a CRBSI. Indwelling season was defined as the season in which more than half of the duration time of the PICC occurred. PICC adjustment was subsequently done after X-ray location check if the tip was not in the SVC. PICC dislodgment was defined as a change in the catheter's location of more than $2 \mathrm{~cm}$ from the original location which did not influence the catheter's function (ie, the catheter was still in the central vein). ${ }^{1}$

\section{Statistical analysis}

The rates of local infection and CRBSI were expressed by percentage and per 1,000 catheter days. Demographic characteristics and potential risk factors for patients were summarized by descriptive statistics. Some numeric variables were transformed into ordered categorical variables for further analysis. Univariate and multivariable conditional logistic regression analyses of variables that were potential risk factors of PICC-related infection were utilized. Variables that were statistically significant with $P<0.1$ as well as those that could have clinical meaning based on the medical literature were retained in the final multivariable model. A backward stepwise method was used for multivariable conditional logistic regression models. Analyses were performed using SPSS 17.0 software and all statistical tests were two-tailed; $P<0.05$ was considered statistically significant. 


\section{Results}

\section{Patient characteristics}

During our study period, 912 cancer patients were included and followed up to catheter removal in the study for a total of 96,307 catheter days (range 12-412 days; mean 105.60 days). Three hundred and seventy-eight patients were male and 534 patients were female, with a mean age of 53.93 years (range 18-85 years). Eight hundred and thirteen PICCs (89.14\%) were removed due to completion of therapy. Ninety-nine (10.86\%) were removed because of complications or patient request; $43(4.71 \%)$ of these were removed due to infective complications, $47(5.15 \%)$ were removed due to other complications, and nine $(0.99 \%)$ were removed because of the patient's request. The detailed reasons for PICC removal are listed in Table 2. The main patient characteristics and variables are described according to the infection status in Table 3. There were significant differences in patients' ages and diagnoses.

\section{General results of PICC-related infection}

Ninety-four (0.98/1,000 catheter days; $10.31 \%$ ) PICCs developed PICC-related infection among the 912 PICCs included in our study. Of these infections, 46 (5.04\%) were exit-site infection, $43(4.71 \%)$ were catheter bacterial colonization, and five $(0.55 \%)$ were PICC-related bloodstream infection. The median time from catheter insertion to infection was 98.26 days (7-267 days) (Table 4). The ranges of exit-site infection diameters were from $1 \times 1 \mathrm{~cm}$ to $8 \times 10 \mathrm{~cm}$. Of the 43 PICCs which had bacterial colonization, 40 were removed at the end of treatment and three were removed because of catheter occlusion.

With respect to microbiology, most infections were caused by Gram-positive bacteria (70.18\%), and fewer infections were related to Gram-negative bacteria (21.05\%) and Candida spp. (8.77\%) (Table 5). Gram-positive bacteria in our study had a high drug resistance rate to penicillin, ciprofloxacin, clindamycin, and erythromycin, while

Table 2 Reasons for PICC removal

\begin{tabular}{lll}
\hline Condition & $\begin{array}{l}\text { Number of } \\
\text { PICCs }\end{array}$ & Percentage \\
\hline Completion of therapy & 813 & 89.14 \\
Catheter-related infection & 43 & 4.71 \\
Other complications & 47 & 5.15 \\
Phlebitis & 17 & 1.86 \\
Catheter occlusion & 10 & 1.10 \\
Vein thrombosis & 9 & 0.99 \\
Catheter dislodgment & 7 & 7.68 \\
Catheter leaking or broken & 4 & 4.39 \\
Patient request & 9 & 0.99 \\
\hline
\end{tabular}

Abbreviation: PICC, peripherally inserted central catheter.
Gram-negative bacteria had a high drug resistance rate to co-trimoxazole, ampicillin, aztreonam, ceftazidime, and tobramycin. Tables 6 and 7 list the detailed drug resistance rates of bacteria.

\section{Analysis of CRI risks}

Seventeen variables were used in the bivariate analysis including age, gender, tumor type, number of punctures, fixing method, tip position, catheter care delay, insertion arm, indwelling time, insertion unit, indwelling season, catheter brand, insertion vein, PICC adjustments, and PICC dislodgment. Of these, fixing method, tip position, catheter care delay, and indwelling season were associated with PICC infection $(P<0.05)$ (Table 8$)$. To further analyze the risk factors for PICC-related infection, multivariate analyses for these risk factors and two possible risk factors of indwelling time $(P=0.069)$ and PICC dislodgment ( $P=0.064)$ were performed. In our multivariable models, fixing method, tip position, catheter care delay, and indwelling season were associated with PICC infection $(P<0.05)$. StatLock fixing (odds ratio $[\mathrm{OR}]=0.555,95 \%$ confidence interval [CI]: 0.326-0.945) and tip position located in the lower one-third of the SVC (OR $=0.340$, 95\% CI: 0.202-0.571) were associated with a lower PICC infection rate. Catheter care delay ( $\mathrm{OR}=2.612$, 95\% CI: 1.373-4.969) and indwelling mostly in summer $(\mathrm{OR}=4.784,95 \% \mathrm{CI}: 2.681-8.538)$ were associated with a higher PICC infection incidence. Results of the multivariate analyses are presented in Table 9.

\section{Discussion}

For PICC-related infection, most studies focused emphasis on CRBSI, which was more serious and could increase patients' morbidity, prolong hospitalization time, and aggravate medical cost. Little was known on the comprehensive rate of CRI, containing exit-site infection, bacterial colonization, and CRBSI. Notably, our study prospectively investigated the incidence and risk factors of these different kinds of infection. The overall incidence of CRI in our study was 0.98 per 1,000 catheter days (10.31\%), with the median time from catheter insertion to infection 98.26 days (7-267 days). Risk factors associated with PICC-related infection included: catheter care delay, indwelling mostly in summer, film fixing, and tip position located in the upper two-thirds of the SVC. These results provide information about important, potentially modifiable risk factors associated with PICC-related infection and could serve to improve clinical practice.

In our study, the median duration of PICCs was approximately 4 months, with $73 \%$ of PICCs lasting more than 90 days 
Table 3 General characteristics and CRI incidence

\begin{tabular}{|c|c|c|c|c|c|}
\hline Variable & $\begin{array}{l}\text { Patients } \\
\mathrm{N}=912\end{array}$ & $\begin{array}{l}\text { Patients with } \\
\text { CRI (n=94) (\%) }\end{array}$ & $\begin{array}{l}\text { Patients without } \\
\text { CRI (n=8I8) (\%) }\end{array}$ & $\chi^{2}$ & $P$-value \\
\hline Gender & & & & 1.203 & 0.273 \\
\hline Male & 378 & $34(9.0)$ & $344(91.0)$ & & \\
\hline Female & 534 & $60(11.2)$ & $474(88.8)$ & & \\
\hline Age range (years) & & & & 17.310 & $0.002^{* *}$ \\
\hline $18-30$ & 67 & $\mathrm{I}(\mathrm{I} .5)$ & $66(98.5)$ & & \\
\hline $31-42$ & 126 & $15(11.9)$ & III (88.I) & & \\
\hline $43-54$ & 238 & 33 (13.9) & $205(86.1)$ & & \\
\hline $55-66$ & 277 & $35(12.6)$ & $242(87.4)$ & & \\
\hline$\geq 67$ & 204 & $10(4.9)$ & $194(95.1)$ & & \\
\hline Underlying cancer & & & & 15.355 & $0.018^{*}$ \\
\hline Breast & 258 & $37(14.3)$ & $221(85.7)$ & & \\
\hline Lung & 223 & $14(6.3)$ & 209 (93.7) & & \\
\hline Gastrointestinal $^{a}$ & 251 & 31 (12.4) & $220(87.6)$ & & \\
\hline Head and neck ${ }^{\mathrm{b}}$ & 34 & $5(14.7)$ & $29(85.3)$ & & \\
\hline Gynecologic ${ }^{c}$ & 69 & $3(4.3)$ & $66(95.7)$ & & \\
\hline Hematologic ${ }^{d}$ & 70 & $4(5.7)$ & $66(94.3)$ & & \\
\hline Other cancer ${ }^{\mathrm{e}}$ & 7 & $0(0.0)$ & $7(100.0)$ & & \\
\hline Indwelling season & & & & 49.181 & $0.000^{* *}$ \\
\hline Spring or autumn & 356 & $17(4.8)$ & 339 (95.2) & & \\
\hline Summer & 292 & $60(20.5)$ & $232(79.5)$ & & \\
\hline Winter & 264 & $17(6.4)$ & $247(93.6)$ & & \\
\hline Tumor type & & & & 1.730 & 0.188 \\
\hline Solid tumor & 842 & $90(10.7)$ & $752(89.3)$ & & \\
\hline Hematological malignancy & 70 & $4(5.7)$ & $66(94.3)$ & & \\
\hline Indwelling time & & & & 4.634 & $0.03 I^{*}$ \\
\hline$<60$ days & 335 & $25(7.5)$ & $310(92.5)$ & & \\
\hline$\geq 60$ days & 577 & $69(12.0)$ & $508(88.0)$ & & \\
\hline Insertion vein & & & & 0.021 & 0.990 \\
\hline Basilic & 495 & $51(10.3)$ & $444(89.7)$ & & \\
\hline Brachial & 209 & $22(10.5)$ & $187(89.5)$ & & \\
\hline Cephalic & 208 & $21(10.1)$ & $187(89.9)$ & & \\
\hline Insertion arm & & & & 0.211 & 0.646 \\
\hline Left & 368 & $40(10.9)$ & $328(89.1)$ & & \\
\hline Right & 544 & $54(9.9)$ & $490(90.1)$ & & \\
\hline Insertion unit & & & & 0.099 & 0.753 \\
\hline Outpatient OR & 470 & $47(10.0)$ & $423(90.0)$ & & \\
\hline Ward & 442 & $47(10.6)$ & $395(89.4)$ & & \\
\hline PICC adjustments & & & & 0.003 & 0.958 \\
\hline Yes & 118 & $12(10.2)$ & $106(89.8)$ & & \\
\hline No & 794 & $82(10.3)$ & $712(89.7)$ & & \\
\hline PICC dislodgment & & & & 8.815 & $0.003^{* *}$ \\
\hline Yes & 54 & $12(22.2)$ & $42(77.8)$ & & \\
\hline No & 858 & $82(9.6)$ & $776(90.4)$ & & \\
\hline Tip position & & & & 17.270 & $0.000 * *$ \\
\hline Upper $2 / 3$ of SVC & 515 & $72(14.0)$ & $443(86.0)$ & & \\
\hline Lower I/3 of SVC & 397 & $22(5.5)$ & $375(94.5)$ & & \\
\hline Fixing method & & & & 4.699 & $0.030^{*}$ \\
\hline Film-fixed & 618 & $73(11.8)$ & $545(88.2)$ & & \\
\hline StatLock-fixed & 294 & $21(7.1)$ & $273(92.9)$ & & \\
\hline Catheter brand & & & & 0.036 & 0.850 \\
\hline BD (Franklin Lakes, NJ, USA) & 216 & $23(10.6)$ & $193(89.4)$ & & \\
\hline Bard (Salt Lake City, UT, USA) & 696 & $71(10.2)$ & $625(89.8)$ & & \\
\hline
\end{tabular}

Notes: $* P<0.05 ; * * P<0.01$. a Gastric cancer, colon cancer, rectal cancer, liver cancer, pancreatic cancer. ${ }^{b}$ Thyroid cancer, nasopharyngeal carcinoma, laryngeal carcinoma, mouth cancer. ${ }^{c}$ Cervical cancer, ovarian cancer, endometrial carcinoma, choriocarcinoma. ${ }^{d}$ Leukemia, multiple myeloma, lymphoma. ${ }^{\circ}$ Endocrine and neurologic cancer. Abbreviations: CRI, catheter-related infection; OR, operation room; PICC, peripherally inserted central catheter; SVC, superior vena cava.

and a few reaching to 1 year. The CRBSI incidence $(0.05 / 1,000$ catheter days; $0.55 \%$ ) and overall PICC-related infection incidence $(0.98 / 1,000$ catheter days; $10.31 \%)$ in our study are lower than most published data. Al Raiy et al reported a 2.3 per 1,000 catheter-days incidence of CRBSI with the median time to development of infection 23 days in their prospective study. ${ }^{5}$ Ong et al reported an overall incidence of 1.6 per 1,000 catheter days in the proximal valve polyurethane and distal valve silicone PICCs. ${ }^{16}$ Ajenjo et al found a rate of 3.13 CRBSIs per 1,000 catheter days in hospitalized patients in a 
Table 4 Different kinds of catheter-related infection and incidence

\begin{tabular}{lllll}
\hline Infection type & Patients $\mathbf{( N )}$ & Catheter days & Median time to infection (days) & Incidence/I,000 catheter days (\%) \\
\hline Exit-site infection & 46 & 4,116 & 89.48 & $0.48(5.04)$ \\
Bacterial colonization & 43 & 4,945 & 115 & $0.45(4.71)$ \\
CRBSI & 5 & 175 & 35 & $0.05(0.55)$ \\
Total & 94 & 9,236 & 98.26 & $0.98(10.31)$ \\
\hline
\end{tabular}

Abbreviation: CRBSI, catheter-related bloodstream infection.

retrospective study. ${ }^{17}$ Maki et al's systematic review reported a pooled PICC infection incidence of 2.1 per 1,000 catheter days. ${ }^{18}$ These studies included PICCs used for critically ill, cancer, and nutritionally deplete patients. Studies on PICC infection in cancer patients are fewer. Walshe et al reported an infection incidence of 2.5/1,000 catheter days resulting in PICC removal in a prospective study conducted in $2002 .{ }^{19}$ Their study was to investigate all the complications of PICC in adults and pediatric patients with cancer, but it did not clarify the CRI diagnostic criteria in the study. The reported incidence of PICC-related bloodstream infection in cancer patients has been reported to be $0-7.5 / 1,000$ catheter days. ${ }^{8,12,13}$ Chopra et al's meta-analysis found rates of PICC-associated CRBSI were similar for patients with cancer, those who were critically ill, and those requiring total parental nutrition. ${ }^{7}$ Although our study was prospective in design and we cultured all the catheter tips, the CRI incidence was still lower than the published data. The reasons may be as follows: 1) all the PICCs used in our study were 4 Fr in lumen. In Chopra et al's study, more lumens were associated not only with greater risk, but also earlier time to infection. ${ }^{2}$ 2) All the PICCs were inserted for chemotherapy, and the infusion time was relatively shorter for only chemotherapy. Moreover, patients with PICCs were

Table 5 Microbiology of catheter tip cultures

\begin{tabular}{ll}
\hline Organism & $\begin{array}{l}\text { Number of } \\
\text { infections }^{\text {a }}(\%)\end{array}$ \\
\hline Gram-positive bacteria & $40(70.18)$ \\
Staphylococcus epidermidis & $14(24.56)$ \\
Other coagulase-negative staphylococci & $13(22.81)$ \\
Staphylococcus aureus & $6(10.53)$ \\
Staphylococcus haemolyticus & $3(5.26)$ \\
Enterococcus sp. & $2(3.51)$ \\
Other Gram-positive bacteria ${ }^{b}$ & $2(3.51)$ \\
Gram-negative bacteria & $12(21.05)$ \\
Pseudomonas sp. & $6(10.53)$ \\
Klebsiella sp. & $4(7.02)$ \\
Escherichia coli & $2(3.51)$ \\
Fungi & $5(8.77)$ \\
Candida spp. & $5(8.77)$ \\
\hline
\end{tabular}

Notes: ${ }^{\text {TT }}$ The total number was not 48 owing to polymicrobial infections. ${ }^{b}$ Streptococcus spp., Brevibacterium flavum.

Abbreviation: sp., species. mostly at home during their catheter time. It was reported that the risk of PICC infection was usually considered to be lower than one episode/1,000 catheter days in the outpatient setting. ${ }^{13}$ Chopra et al's meta-analysis found a tenfold greater risk of CRBSI among hospitalized patients (5.2\%) than among outpatients who received PICCs $\left.(0.5 \%) .^{7} 3\right)$ In our investigation, all PICCs were inserted at the upper mid-arm by ultrasoundguided puncture and we had PICC specialist nurses to care for the PICCs, which may be another reason for the lower infection rate. 4) Patients in our study mostly had solid tumors and fewer had hematological malignancies. It is a well-known fact that catheter infection is high in hematological malignancies. In a prospective study of adult patients with both hematologic and solid tumor malignancies, Mollee et al found that patients with aggressive hematological malignancies were at a higher risk of infection than those with other oncological diagnoses. ${ }^{13}$

In our study, Gram-positive organisms were the most common pathogens associated with infection (70.18\%), whereas Gram-negative bacteria were responsible for $21.05 \%$ and fungi for $8.77 \%$. Similar to prior studies, Staphylococcus epidermidis and coagulase-negative staphylococci were the most common causative organisms for CRI, while Pseudomonas sp. and Klebsiella sp. were the most prevalent Gram-negative bacteria. ${ }^{12}$ But most of the bacterial colonization were asymptomatic and were not found until catheter tip culture at the time of removal, which was a novel finding in our study with no former report.

It is worth noting that StatLock fixing ( $O R=0.555,95 \%$ CI: $0.326-0.945)$ and tip position located in the lower onethird of the SVC (OR $=0.340,95 \% \mathrm{CI}: 0.202-0.571)$ were associated with a lower PICC infection rate in our analysis. StatLock is a sutureless alternative to tape or suture for securement of PICCs. This device consists of a sterile, latexfree, adhesive-backed anchor pad that secures onto the PICC with a locking clamp. ${ }^{20}$ Yamamoto et al found significantly fewer PICC-related bloodstream infections in the StatLock group in their study. ${ }^{20}$ StatLock performs well in preventing catheter-related dislodgment and migration, which may be the reason for fewer PICC-related infections. It has been recommended tip position be in the distal third of the SVC 
Table 6 Drug resistance rates of main Gram-positive bacteria

\begin{tabular}{|c|c|c|c|c|c|c|c|}
\hline \multirow[t]{3}{*}{ Antibiotic } & $\begin{array}{l}\text { Staphylococcus } \\
\text { epidermidis }\end{array}$ & $\begin{array}{l}\text { Other coagulase- } \\
\text { negative } \\
\text { staphylococci }\end{array}$ & $\begin{array}{l}\text { Staphylococcus } \\
\text { aureus }\end{array}$ & $\begin{array}{l}\text { Staphylococcus } \\
\text { haemolyticus }\end{array}$ & $\begin{array}{l}\text { Enterococcus } \\
\text { sp. }\end{array}$ & $\begin{array}{l}\text { Other Gram- } \\
\text { positive } \\
\text { bacteria }\end{array}$ & \multirow{3}{*}{$\begin{array}{l}\text { Total drug } \\
\text { resistance } \\
\text { rate } \\
\text { (\%) }\end{array}$} \\
\hline & $n=14$ & $n=13$ & $n=6$ & $n=3$ & $n=2$ & $n=2$ & \\
\hline & $R / S$ & $\mathbf{R} / \mathbf{S}$ & $R / S$ & $R / S$ & $R / S$ & $R / S$ & \\
\hline Penicillin & $10 / 4$ & $10 / 3$ & $4 / 2$ & $2 / 1$ & $2 / 0$ & $2 / 0$ & 75.0 \\
\hline Clindamycin & $7 / 7$ & $8 / 5$ & $3 / 3$ & $2 / 1$ & $1 / 1$ & $2 / 0$ & 57.5 \\
\hline Erythromycin & $8 / 6$ & $5 / 8$ & $4 / 2$ & $2 / 1$ & $2 / 0$ & $2 / 0$ & 57.5 \\
\hline Ciprofloxacin & $7 / 7$ & $6 / 7$ & $3 / 3$ & $\mathrm{I} / 2$ & $2 / 0$ & $2 / 0$ & 52.5 \\
\hline Gentamicin & $6 / 8$ & $6 / 7$ & $1 / 5$ & $1 / 2$ & $2 / 0$ & $0 / 2$ & 40.0 \\
\hline Imipenem & $3 / 11$ & $2 / 11$ & $2 / 4$ & $0 / 3$ & $0 / 2$ & $0 / 2$ & 17.5 \\
\hline Levofloxacin & $6 / 8$ & $7 / 6$ & $2 / 4$ & $\mathrm{I} / 2$ & $0 / 2$ & $0 / 2$ & 40.0 \\
\hline Dalfopristin & $1 / 13$ & $0 / 13$ & $0 / 6$ & $0 / 3$ & $2 / 0$ & $0 / 2$ & 7.5 \\
\hline Rifampicin & $2 / 12$ & $1 / 12$ & $0 / 6$ & $0 / 3$ & $0 / 2$ & $0 / 2$ & 7.5 \\
\hline Piperacillin & $7 / 7$ & $6 / 7$ & $2 / 4$ & $1 / 2$ & $2 / 0$ & $1 / 1$ & 47.5 \\
\hline Vancomycin & $0 / 14$ & $0 / 13$ & $0 / 6$ & $0 / 3$ & $0 / 2$ & $0 / 2$ & 0 \\
\hline Teicoplanin & $4 / 10$ & $5 / 8$ & $0 / 6$ & $1 / 2$ & $0 / 2$ & $1 / 1$ & 27.5 \\
\hline
\end{tabular}

Abbreviations: R/S, resistance/sensitivity; sp., species.

or close to the junction of the SVC and right atrium, where there is maximum blood flow, and this position was reported to have a lower PICC-related thrombosis incidence. ${ }^{21}$ It was reported that $83 \%$ of PICCs which had first been radiographically confirmed to be in the proper position had migrated into the innominate or subclavian veins. ${ }^{22}$ Tip positions in the upper two-thirds of the SVC are more likely to migrate, which may be the reason for higher thrombosis and infection rates. Indwelling mostly in summer ( $\mathrm{OR}=4.784,95 \%$ CI: $2.681-8.538)$ and catheter care delay (OR $=2.612,95 \%$ CI: $1.373-4.969)$ were the statistically significant risk factors in our study. It was reported that the major sources of microorganisms of PICC infection were from the patient's own skin and the hands of medical personnel. The number of colonization bacteria of the skin was influenced by seasons.
In summer, along with high temperature and a humid environment, the colonization might have increased, which may be the reason for a higher infection rate. We classified age into young (18-45 years), middle age (46-65 years), and old ( $>65$ years) and classified diagnosis into solid tumor and hematological malignancy in order to conduct logistic regression analysis. It is worth mentioning that although there were significance differences in the stratified age and different diagnoses in CRI incidence, we did not find these were risk factors of PICC-related infection.

There are several limitations in this study. Firstly, all the PICCs in our study were one-lumen PICCs; we failed to explore the relevance between number of lumens and PICC-related infection. Secondly, although most bacterial colonization was asymptomatic and found at the time of

Table 7 Drug resistance rates of main Gram-positive bacteria

\begin{tabular}{|c|c|c|c|c|}
\hline \multirow[t]{2}{*}{ Antibiotic } & \multirow{2}{*}{$\begin{array}{l}\text { Pseudomonas sp. } \\
\mathrm{n}=6 \\
\mathrm{R} / \mathrm{S}\end{array}$} & \multirow{2}{*}{$\begin{array}{l}\text { Klebsiella sp. } \\
\mathrm{n}=4 \\
\mathrm{R} / \mathrm{S}\end{array}$} & \multirow{2}{*}{$\begin{array}{l}\text { Escherichia coli } \\
\mathrm{n}=\mathbf{2} \\
\mathrm{R} / \mathrm{S}\end{array}$} & \multirow[t]{2}{*}{$\begin{array}{l}\text { Total drug resistance rate } \\
\text { (\%) }\end{array}$} \\
\hline & & & & \\
\hline Ceftriaxone & $1 / 5$ & $1 / 3$ & $\mathrm{I} / \mathrm{I}$ & 25.0 \\
\hline Cefazolin & $2 / 4$ & $3 / 1$ & $0 / 2$ & 41.7 \\
\hline Aztreonam & $3 / 3$ & $3 / 1$ & $1 / 1$ & 58.3 \\
\hline Amikacin & $2 / 4$ & $1 / 3$ & $0 / 2$ & 25.0 \\
\hline Ceftazidime & $3 / 3$ & $3 / 1$ & $\mathrm{I} / \mathrm{I}$ & 58.3 \\
\hline Cefepime & $2 / 4$ & $2 / 2$ & $\mathrm{I} / \mathrm{I}$ & 41.7 \\
\hline Gentamicin & $3 / 3$ & $1 / 3$ & $\mathrm{I} / \mathrm{I}$ & 41.7 \\
\hline Imipenem & $1 / 5$ & $0 / 4$ & $0 / 2$ & 8.3 \\
\hline Levofloxacin & $3 / 3$ & $1 / 3$ & $0 / 2$ & 33.3 \\
\hline Ampicillin & $4 / 2$ & $2 / 2$ & $2 / 0$ & 66.7 \\
\hline Tobramycin & $5 / 1$ & $3 / 1$ & $\mathrm{I} / \mathrm{I}$ & 75.0 \\
\hline Cotrimoxazole & $4 / 2$ & $1 / 3$ & $\mathrm{I} / \mathrm{I}$ & 50.0 \\
\hline
\end{tabular}

Abbreviations: R/S, resistance/sensitivity; sp., species. 
Table 8 Univariable (adjusted) logistic regression analyses for PICC-related infection

\begin{tabular}{|c|c|c|c|}
\hline Variable & Odds ratio & $95 \% \mathrm{Cl}$ & $P$-value \\
\hline \multicolumn{4}{|l|}{ Age (years) } \\
\hline $18-45$ & I & Ref & Ref \\
\hline $46-65$ & 1.285 & $0.730-2.263$ & 0.384 \\
\hline$>65$ & 1.378 & $0.693-2.74 I$ & $0.36 \mathrm{I}$ \\
\hline \multicolumn{4}{|l|}{ Gender } \\
\hline Male & I & Ref & Ref \\
\hline Female & 1.230 & $0.754-2.005$ & 0.407 \\
\hline \multicolumn{4}{|l|}{ Tumor type } \\
\hline Liquid malignancy & 1 & Ref & Ref \\
\hline Solid tumor & 1.991 & $0.656-6.040$ & 0.224 \\
\hline \multicolumn{4}{|l|}{ Number of punctures } \\
\hline I & I & Ref & Ref \\
\hline 2 & 0.847 & $0.423-1.696$ & 0.639 \\
\hline 3 or more & 0.595 & $0.252-1.403$ & 0.235 \\
\hline \multicolumn{4}{|l|}{ Fixing method } \\
\hline Film-fixed & 1 & Ref & Ref \\
\hline StatLock-fixed & 0.534 & $0.312-0.916$ & $0.023^{*}$ \\
\hline \multicolumn{4}{|l|}{ Tip position } \\
\hline Upper $2 / 3$ of SVC & 1 & Ref & Ref \\
\hline Lower $1 / 3$ of SVC & 0.346 & $0.204-0.589$ & $0.000^{* *}$ \\
\hline \multicolumn{4}{|l|}{ Catheter care delay } \\
\hline No & I & Ref & Ref \\
\hline Yes & 3.507 & I.607-7.656 & $0.002^{* *}$ \\
\hline \multicolumn{4}{|l|}{ Insertion arm } \\
\hline Right & 1 & Ref & Ref \\
\hline Left & 1.205 & $0.784-1.943$ & 0.443 \\
\hline \multicolumn{4}{|l|}{ Indwelling time } \\
\hline$<60$ days & I & Ref & Ref \\
\hline$\geq 60$ days & 1.605 & $0.963-2.675$ & 0.069 \\
\hline \multicolumn{4}{|l|}{ Insertion unit } \\
\hline Ward & I & Ref & Ref \\
\hline Outpatient OR & $0.94 I$ & $0.595-1.489$ & 0.796 \\
\hline \multicolumn{4}{|l|}{ Indwelling season } \\
\hline Spring or autumn & I & Ref & Ref \\
\hline Summer & 4.857 & $2.702-8.731$ & $0.000^{* *}$ \\
\hline Winter & 1.294 & $0.636-2.635$ & 0.477 \\
\hline \multicolumn{4}{|l|}{ Catheter brand } \\
\hline Bard (Salt Lake City, UT, USA) & I & Ref & Ref \\
\hline BD (Franklin Lakes, NJ, USA) & 1.059 & $0.62 \mid-1.808$ & 0.832 \\
\hline \multicolumn{4}{|l|}{ Insertion vein } \\
\hline Cephalic & I & Ref & Ref \\
\hline Basilic & 1.062 & $0.596-1.894$ & 0.838 \\
\hline Brachial & 0.675 & $0.308-|.48|$ & 0.675 \\
\hline \multicolumn{4}{|l|}{ PICC adjustments } \\
\hline No & I & Ref & Ref \\
\hline Yes & 1.107 & $0.557-2.200$ & 0.771 \\
\hline \multicolumn{4}{|l|}{ PICC dislodgment } \\
\hline No & I & Ref & Ref \\
\hline Yes & 2.061 & $0.958-4.433$ & 0.064 \\
\hline
\end{tabular}

Notes: $* P<0.05 ; * * P<0.01$.

Abbreviations: $\mathrm{Cl}$, confidence interval; OR, operation room; PICC, peripherally inserted central catheter; Ref, reference; SVC, superior vena cava.

catheter removal, we did not follow up the patients after PICC removal. Thirdly, we did not do further study on the treatment measures for PICC-related infection. Although there are some limitations, our study has important strengths. To our knowledge, this is the largest prospective study on PICC-related infection among cancer patients. In addition,
Table 9 Multivariable (adjusted) logistic regression analysis of risk factors associated with PICC infection

\begin{tabular}{|c|c|c|c|}
\hline Variable & Odds ratio & $95 \% \mathrm{Cl}$ & $P$-value \\
\hline \multicolumn{4}{|l|}{ Fixing method } \\
\hline Film-fixed & 1 & Ref & Ref \\
\hline StatLock-fixed & 0.555 & $0.326-0.945$ & $0.030 *$ \\
\hline \multicolumn{4}{|l|}{ Tip position } \\
\hline Upper $2 / 3$ of SVC & 1 & Ref & Ref \\
\hline Lower $1 / 3$ of SVC & 0.340 & $0.202-0.57 \mid$ & $0.000^{* *}$ \\
\hline \multicolumn{4}{|l|}{ Catheter care delay } \\
\hline No & 1 & Ref & Ref \\
\hline Yes & 2.612 & $1.373-4.969$ & $0.003^{* *}$ \\
\hline \multicolumn{4}{|l|}{ Indwelling time } \\
\hline$<60$ days & 1 & Ref & Ref \\
\hline$\geq 60$ days & 1.550 & $0.937-2.565$ & 0.088 \\
\hline \multicolumn{4}{|l|}{ Indwelling season } \\
\hline Spring or autumn & I & Ref & Ref \\
\hline Summer & 4.784 & $2.68 I-8.538$ & $0.000 * *$ \\
\hline Winter & 1.324 & $0.655-2.676$ & 0.434 \\
\hline \multicolumn{4}{|l|}{ PICC dislodgment } \\
\hline No & 1 & Ref & Ref \\
\hline Yes & 1.952 & $0.98 I-4.154$ & 0.082 \\
\hline
\end{tabular}

Notes: $* P<0.05 ; * * P<0.01$.

Abbreviations: $\mathrm{Cl}$, confidence interval; $\mathrm{PICC}$, peripherally inserted central catheter; Ref, reference; SVC, superior vena cava.

we cultured all the PICC tips at the time of PICC removal, making our study more accurate in PICC-related infection rate than former studies.

\section{Conclusion}

PICC-related bloodstream infection was lower in oncology patients receiving chemotherapy, while with a higher asymptomatic bacterial colonization rate compared to former reports, which should be further studied. StatLock fixing and tip position located in the lower one-third of the SVC were protective factors against PICC-related infection, while catheter care delay and indwelling mostly in summer were risk factors. Policy and measures targeting these factors may be necessary to reduce the risk of PICC-related infection.

\section{Acknowledgments}

We acknowledge the PICC team nurses in our hospital. This work was supported by a medical science and technology development project for Shandong Province (2009 HZ024).

\section{Disclosure}

The authors report no conflicts of interest in this work.

\section{References}

1. Li J, Fan YY, Xin MZ, et al. A randomised, controlled trial comparing the long-term effects of peripherally inserted central catheter placement in chemotherapy patients using B-mode ultrasound with modified Seldinger technique versus blind puncture. Eur J Oncol Nurs. 2014;18(1): 94-103. 
2. Chopra V, Ratz D, Kuhn L, Lopus T, Chenoweth C, Krein S. PICCassociated bloodstream infections: prevalence, patterns, and predictors. Am J Med. 2014;127(4):319-328.

3. Tian G, Zhu Y, Qi L, Guo F, Xu H. Efficacy of multifaceted interventions in reducing complications of peripherally inserted central catheter in adult oncology patients. Support Care Cancer. 2010;18(10): 1293-1298.

4. Moran J, Colbert CY, Song J, et al. Screening for novel risk factors related to peripherally inserted central catheter-associated complications. J Hosp Med. 2014;9(8):481-489.

5. Al Raiy B, Fakih MG, Bryan-Nomides N, et al. Peripherally inserted central venous catheters in the acute care setting: a safe alternative to high-risk short-term central venous catheters. Am J Infect Control. 2010; 38(2):149-153.

6. Gunst M, Matsushima K, Vanek S, Gunst R, Shafi S, Frankel H. Peripherally inserted central catheters may lower the incidence of catheter-related blood stream infections in patients in surgical intensive care units. Surg Infect (Larchmt). 2011;12(4):279-282.

7. Chopra V, O'Horo JC, Rogers MA, Maki DG, Safdar N. The risk of bloodstream infection associated with peripherally inserted central catheters compared with central venous catheters in adults: a systematic review and meta-analysis. Infect Control Hosp Epidemiol. 2013;34(9):908-918.

8. Lim MY, Al-Kali A, Ashrani AA, et al. Comparison of complication rates of Hickman $\left({ }^{\circledR}\right)$ catheters versus peripherally inserted central catheters in patients with acute myeloid leukemia undergoing induction chemotherapy. Leuk Lymphoma . 2013;54(6):1263-1267.

9. Skaff ER, Doucette S, McDiarmid S, Huebsch L, Sabloff M. Vascular access devices in leukemia: a retrospective review amongst patients treated at the Ottawa Hospital with induction chemotherapy for acute leukemia. Leuk Lymphoma. 2012;53(6):1090-1095.

10. Worth LJ, Seymour JF, Slavin MA. Infective and thrombotic complications of central venous catheters in patients with hematological malignancy: prospective evaluation of nontunneled devices. Support Care Cancer. 2009;17(7):811-818.

11. Cortelezzia A, Fracchiolla NS, Maisonneuve P, et al. Central venous catheter-related complications in patients with hematological malignancies: a retrospective analysis of risk factors and prophylactic measures. Leuk Lymphoma. 2003;44(9):1495-1501.
12. Cotogni P, Pittiruti M, Barbero C, Monge T, Palmo A, Boggio Bertinet D Catheter-related complications in cancer patients on home parenteral nutrition: a prospective study of over 51,000 catheter days. JPEN J Parenter Enteral Nutr. 2013;37(3):375-383.

13. Mollee P, Jones M, Stackelroth J, et al. Catheter-associated bloodstream infection incidence and risk factors in adults with cancer: a prospective cohort study. J Hosp Infect. 2011;78(1):26-30.

14. Milstone AM, Reich NG, Advani S, et al. Catheter dwell time and CLABSIs in neonates with PICCs: a multicenter cohort study. Pediatrics. 2013;132(6):e1609-e1615.

15. O'Grady NP, Alexander M, Burns LA, et al; Healthcare Infection Control Practices Advisory Committee. Guidelines for the prevention of intravascular catheter-related infections. Am J Infect Control. 2011; 39(4 Suppl 1):S1-S34

16. Ong CK, Venkatesh SK, Lau GB, Wang SC. Prospective randomized comparative evaluation of proximal valve polyurethane and distal valve silicone peripherally inserted central catheters. J Vasc Interv Radiol. 2010;21(8):1191-1196.

17. Ajenjo MC, Morley JC, Russo AJ, et al. Peripherally inserted central venous catheter-associated bloodstream infections in hospitalized adult patients. Infect Control Hosp Epidemiol. 2011;32(2):125-130.

18. Maki DG, Kluger DM, Crnich CJ. The risk of bloodstream infection in adults with different intravascular devices: a systematic review of 200 published prospective studies. Mayo Clin Proc. 2006;81(9): 1159-1171.

19. Walshe LJ, Malak SF, Eagan J, Sepkowitz KA. Complication rates among cancer patients with peripherally inserted central catheters. J Clin Oncol. 2002;20(15):3276-3281.

20. Yamamoto AJ, Solomon JA, Soulen MC, et al. Sutureless securement device reduces complications of peripherally inserted central venous catheters. J Vasc Interv Radiol. 2002;13(1):77-81.

21. Kearns PJ, Coleman S, Wehner JH. Complications of long arm-catheters: a randomized trial of central vs peripheral tip location. JPENJ Parenter Enteral Nutr. 1996;20(1):20-24.

22. Cowl CT, Weinstock JV, Al-Jurf A, Ephgrave K, Murray JA, Dillon K. Complications and cost associated with parenteral nutrition delivered to hospitalized patients through either subclavian or peripherally-inserted central catheters. Clin Nutr. 2000;19(4):237-243.
Therapeutics and Clinical Risk Management

\section{Publish your work in this journal}

Therapeutics and Clinical Risk Management is an international, peerreviewed journal of clinical therapeutics and risk management, focusing on concise rapid reporting of clinical studies in all therapeutic areas outcomes, safety, and programs for the effective, safe, and sustained use of medicines. This journal is indexed on PubMed Central, CAS,

\section{Dovepress}

EMBase, Scopus and the Elsevier Bibliographic databases. The manuscript management system is completely online and includes a very quick and fair peer-review system, which is all easy to use. Visit http://www.dovepress.com/testimonials.php to read real quotes from published authors. 